\section{REMARKS ON THE MOVEMENTS AND SOUNDS OF THE HEART, AS ILLUSTRA'TED BY THE CASE OF M. GROUX.}

By A.T.H. Waters, lis , Lecturer on Anatomy and Physiology in the Royal Infirmary School of Medicine, !iverpool.

\footnotetext{
[Abstract of a Iriper real before the Lirerpon? IIetical Sociefy.]
}

THE members of the profession have been much interestch of late in the case of M. Groux, in whom there exists a congenital fissure of the sturnum, which renders visible through the integuments and fascix, some of the movements of the heart. Many opinions have been expressed with reforence to the parts brought into view by the peculiar malformation. A recent and somewhat careful examination has enabled me to form an opinion of snme of the more important points of the case, and that opinion I venture to bring forward.

Admitting the following to be the order in which the movements of the heart take place, viz., contraction of auricles, contraction of ventricles (first sound)-pause (during which no muscular action takes place, but which is accompanied by the second sound), followed by contraction of auricles, etc., we proceed to inquire how far the case under consideration, in which there seems to be no abnormal condition of the heart itself, corroborates this view.

The most important points of the case I believe to be the following:-

In the fissure ahout the midlle there exists a tumour which moves in two directions: first, from above downwards; secondly, from below upwards. The first movement diminishes the size of the tumnur, and the second increases it.

At the upper part of the fissure, on pressing firmly backwards, two shocks are felt, in the position in which the aorta is normally placed.

In the lower part of the fissure a movement can be seen and felt in the situation of the right ventricle.

In connexion with the tumour, two pulsations can be felt; one accompanving its contraction, the other its dilatation.

The impulse of the heart is felt in its normal position.

The two sounds of the heart are normal; they do not differ in character from those usually heard, but in some situations they differ in degres.

In connexion with the tumour, under certain circumstances, a bruit is heard.

It is generally arreed that the tumour in the midule of the fissure is the right amicle, and in this opinion I entirely. concur, for the following reasons.

Its position is that of the right auricle. Its downward movement or contraction takes place just before the contraction of the ventricles, and is attended with a drawing or sucking in, to be felt when the skin over it is pinched between the finger and thumb. When respiration is arrested, it becomes distenderl. Its dilatation is attended with an impulse communicated to it chictly, I believe, by the pulsation of the aorta and pulmonary artery, with which it is synchronous. When the sounds of the heart are listened to, and at the same ime a finger is placed on the tumour, its contraction is felt to take place in the interval between the two sounds; it precedes the first and follows the second sound.

With reference to the two shocks felt at the upper part of the fissure, I believe the first to be protuced by the pulsation of the aorta; the second, by the vibration resulting from the closure of the semilunar valves. The first shock is synchronous with the impulse of the heart; the second immediately follows it.

The orlinary sounds are heard as usual over the pro cordial region. When the stethoscope was applied over the base of the great vessels, the sounds seemed to me louder than usual, from the fact that the instrument was placed nearer the source of the sounds. In the uppor part of the fissure the sounds are clear, but not very loud : possibly the sounds pro. duced on the left sile of the heart are more or less isolated when the instrument is applied to this spot.

With regard to the auricular sound, I have as ret heard no satisfactory explanation of it. The most important question with reference to jt is-1s it produced by the contraction of the auricle : and if not, what is its cause? Observation has hitherto taught us that no sound accompanies the contraction of the auricles; and evidence has been afforded that contraction of the ventricles per se, produces no sound. In M. Groux, this peculiar auricular sound is only heard under certain circumstances, which are, that the stethoscope shall be applied over the tumour, and slight pressure be made. It is not hesr. when no pressure is made, nor yet when firm pressure is made. It differs altngether in character from the sounds of the heart; and resembles somewhat the sound produced ly the rush of fluid through a constricted tube. Taking thes facts in consideration, I belicve the sound to be the resul: of the pressure exerted, and not of the contraction of the auri.le. We know that pressure on a vessel, in which blood is cirenlating, by altering its shape and calibre, will produce a somu; and pressure on the auricle, from which blood is being niw. pelle, at each contraction, may also be experted to proluie : sound. We hear the ordinary sounds of the heart withont making use of pressure; and it appears to me that we ongl: to hear the sound produced by the auricular contraction, su! posing it to be constantly produced, under similar circur: stances; but this is not the case, even in M. Groux. Th. sound is only heard when an amount of pinssure is madi. sufficient to alter the shape of the auricle, but not to bring it walls in contact.

The foregoing observations on this interesting case seem to me to confirm the opinions now generally held of the move ments of the heart. Of the two sounds, the case proves nothing more than can be ascertained where no malformation exists. I cannot agree with one observation that has heri made; viz., that the contraction of the tumonr (auricle) take place slowly; it appeared to me to be more rapid than the subsequent dilatation; and this was especially noticed when the skin over the tumour was grasped by the finger and thwnh. Tluis rapirlity of action accords with what is seen in the exposerl heart of the lower mammalia.

\section{CASES OF CEREBRAL SOFTENING, ETC.: WITI REMARKS.}

By Thoyas Inman, M.D., Liverpool.

In a previous number of the British Medicat. Journat, I endeavoured to call the attention of the profession to the fac that the so called threatening or premonitory signs of apoplex were very commonly due to unusual mental distress, prolongei anxiety of mind, the extension of tubercular degeneration, or to some other cause of general debility; that they were, in fact, evidences of defective power in the heart, or of impaired nutrition in the brain; that they were generally coincident with other unimpeachable proofs of constitutional feebleness; and that post mortem examinations proved them to be connected with a degenerate condition of the cerebral arteries and capil. laries. I assumed that, if the symptoms were associated with degeneration of blood-vessels, anything which promoted that process would inevitally tend to aggravate them; and that, if a cure was to be effecterl, it could only be done by improving the vital powers of those parts which were threatened with decay and death. I have also called attention to the extreme frequency with which atheroma in the larger arteries, degeneration of the capillaries, and a fatty condition of the heart, are associated with phthisis; the great probability there is that atheroma is the analogue of tubercle, and, consequently, the strong reason to believe that softening of the brain is, in the majority of instances at least, a process analogous to the softening and breaking up of the lung in cases of tubercular infiltration; that cercbral hemorrbage is, mutatis mutandis, the analogue of hæmoptrsis; and that cerebral softening anı hmmorrhage require for their treatment a plan similar to what we should employ in incipient phthisis. These views receive strong corifirmation from a careful examination of recorded cases of cerebral softening, and its most aggravated form, that of cerebral abscesses. Thus Lcbert, quoted by Dr. J. H. B+nnett, remarks, "that whatever debilitates the individual, predisposes to these affections." Dr. Bennett confirms his state ments; and they base their opinions on upwards of eighty cases. I have myself' met with thirty cases of cercbral softening, and have in all found evidence of phthisis, degeneration o arteries, or other proof of malassimilation. The twenty-seven cases recorded by Andral conspicuously point to the same conclusion.

The following cases, which have recently come under my notice, amply confirm the preceding remarks.

CASE r. J.B., aged 40, a burly Swedish sailor, was admittel into the Northern Hospital on March 14 th, with complete paralysis of the right hand and arm, slight weakness and numbness of the right leg, some confusion in the head, and difficulty of speech. He had had a similar attacli at sea about 
six weeks ago, which had gone off again without treatment. 'The present attack had come on a fortnight previously, during sleep. His complexion was pallid, but in every other respect he seemed very strong. The heart was healthy. There was no headache. I ascertained that the man had been unusually exposed at sea, as his vessel, a steamer, had broken down, and they had been well-nigh wrecked. I ordered him a simple quinine mixture, and full diet with porter. In two days he could move his fingers, but complained of headache. Thinking that this was due to the quinine, I changed it for the tincture of iron. The improvement continued steady, and in ten days the man went to sea, with no perceptible difference between the power of the right and left arms and hands.

CASE II. Mr. — aged $2 \pi$, cashier in a mercantile office, had recently had a hemiplegic attack implicating the whole of the right side of the body. Sensation had almost entirely left the arm, but motion was still present, there being more of weakness than actual paralysis. The history was this. He was always healthy till twelve months ago, when he contracted syphilis. This was followed by iritis, for which he took mercury to salivation. The eyes were still tender, and he had to wear dark glasses : he had been living verv low, rarely taking any flesh meat. He was of a consumptive family, a brother and sister both being affected with the disease. He himself was of spare build and narrow chest; the hands and feet were cold, and the circulation was very languid. The head was confused, the memory impaired, the speech slow. The attack had come on after unusual anxiety, prolonged attention to business, and insufficient food. A tonic plan of treatment was adopted, and as generous a diet recommended as his purse could afford. Improvement was apparent in the sensibility of the arm in two days, and at the end of a fortnight it had completely returned. 'The leg remained numb. but was improved. The whole side was much stronger; the hesitation in speech had disappeared; the circulation was more vigorous. The dark shade was unnecessary for the eve; mental vicrour had re turned; and the patient considered himself aimost well; and I have not seen him since.

CASE IIt. About the same time that I saw this patient I was called in consultation to see Mr. G., aged 6. , who had had a recent attack of hemiplegia, affecting the whole of the right side. The following particulars indicate the nost important points of the history :- He was a man of large size, of regular and temperate habits; he took much out-door exercise, and had never had any serious illness. During the last year he had for the first time been complaining constantly of cold feet and hands. He had also for the first time taken to lying good deal on the sofa, feeling fatigued by his ordinary day's work. He suffered a good deal from cramp in the legs and thighs, and latterly his wife had noticed, when he got up from the sofa, that his right side was weaker than the left. The day before the attack was bitterly cold, yet he had been stand ing about superintending some out.door work in an exposed situation for many hours without any extra clothing on. He was thoroughly chilled, and did not get warm again till near gretting up time next day. He got up and dressed as usual and when in the act of saying his prayers was struck with palsy. There was no loss of consciousness. The surgeon who was called in applied four lecches to the tempie, recommended complete mental quiet, a spare diet, and aperients. In the course of a couple of days he could raise his hand above his head. I saw him on the third day; he could not then raise his hand higher than the shoulder, and was, as the surgeon remarked, evidently enfeebled by the purgatives. I had little to do beyond recommending a cautiously touic plan of treat ment, and a fuller diet. The case is now progressing as favourably as one of cerebral hæmorrhage can be expected to do. I have no reasonable doubt that if the patient had understood the significance of the symptoms which preceded his attack that it might have been indefinitely postponed.

CASE Iv. J. R., aged 40, a labourer was admitted into the Northern Hospital on March 25th under the following circum stances:-A fortnight ago he had been seen casually by the junior house-surgeon, who found him suffering from intense pain in the head and phthisis. A blister to the nape was ordered, and aperient medicine. $\mathrm{He}$ got worse, and at last applied for admission. When I saw him he appeared like a man in typhus - face dusky red; all the motions sluggish to an extreme degree. It seemed as if he took a minute to understand a question, and another to direct his tongue to answer it, or his limbs to act in obedience to the wish formed. There was no paralysis; he said he had no pain; the skin was hot and burning. In consequence of the great similarity of the case to others I had seen, I hazarded the diagnosis that there was tubercle in the brain, and consequent softening. A palliative treatment was ordered, but the man died suddenly in a few hours after my visit.

On post mortem examination both ventricles of the brain were found distended with fluid; both optic thalami and corpora striata were softened; the septum lucidum and fornix were almost diffluent. At the termination of the right choroid plexus there was a mass about the size of an almond, composed of miliary tubercles and tolerably firm recent lymph. A number of miliary tubercles with some inflammatory exudation around them were found on the surfaces of the cerebrum and cerebellum, where they are in contact with the tentorium on the right side. The arteries of the brain were atheromatous to a great extent. In the thorax both lungs were universally adherent to the pleura; miliary tubercles existed throughout the right, and small cavities were found at the apex of the left. The aorta was large, brittle, and studded with atheromatous spots. The heart was healthy. The capillary vessels of the brain, when examined by the microscope, were universally degenerate.

\section{Transactions of 掘rameldes.}

\section{BIRMINGHAM AND MIDLAND COUNTIES BRANCH.}

CASES OF UTERINE HAMORRHAGE, TREATED SUCCESSFULLY BY TRANSFUSION.

By John Wheatcroft, Esq.

[Read February 11th.]

THE subject of transfusion has occupied the attention of the profession more or less for the last century. At one time, it has been made of more importance than it deserved, and has been supposed capable of producing rejuvenescence; at another, it has been deemed as useless, nay, worse than useless-positively dangerous; a host of possible and probable evils, quite frightful to contemplate, being put forward as the result of the operation. But in fact the operation is simple, easy of perfurmance, and, with ordinary care, perfectly safe; for, if I could, totally unacquainted with the modus operandi (practically), succeed with an imperfect and defective instrument, the use of an apparatus like the one of which a drawing is here given must be followed by beneficial results. Here is a dying woman; hemorrhagic gush, or dribble, or flow, has brought the patient into companionship with death; they are already shaking hands; the foe has almost got his victim ;why not dare something, and endeavour all to cheat the monster? And not only in hæmorrhagic loss, but in diverse anæmic conditions, why not inject healthy blood into the exhausted vascular system, and thus peradventure resuscitate? How many discoveries in medicine and surgery have flourished, died, and lived again?

1. Method of Operating. 'The skin over the median basilic rein, being pinched up, is slit up with a common lancet from below upwards. This exposes the vein for an inch in length ; then a probe is passed underneath, slightly loosening its connexions. Then the vein is opened to the extent of a quarter of an inch, and the silver nozzle is inserted, with the open extremity towards the heart. There is no necessity to apply any ligature or bandage; an assistant holding the arm, and pressing slightly with each thumb along the tube, prevents regurgitation. Blood immediately fills the nozzle, thus excluding all air. Water, at about $95^{\circ}$, is then passed into the proper receptacle; hot water is also pumped several times through tho apparatus, so as to effectually warm it. This being expeditiously done, a vein is opened in the arm of the person supplying the blood. As it runs into the receiving-cup, the piston must be brought into action, gradually, firmly, and with moderate quickness; decided strokes being given, so as to impel the blood with energy, and yet not with violence. 'The precise method is indescribable. One stroke of the piston will teach any operator more than a volume of description. I had never seen the operation performed, but the very doing of it taught me how to do it. The tube being connected with the nozzle, the receivingcup should not be allowed to get too full; the patient should have the blood injected as fresh and as warm as possible, with- 